\title{
Oncogenic cAMP responsive element binding protein 1 is overexpressed upon loss of tumor suppressive miR-10b-5p and miR-363-3p in renal cancer
}

\author{
YIFAN LI ${ }^{1-3^{*}}$, DUQUN CHEN ${ }^{1-3^{*}}$, YUCHI LI ${ }^{2,4}$, LU JIN ${ }^{1-3}$, JIAJU LIU $^{1,2,4}$, ZHENGMING SU $^{1,2,4}$, \\ ZHENGYU QI $^{2}$, MIN SHI ${ }^{2}$, ZHIMAO JIANG ${ }^{2}$, LIANGCHAO NI ${ }^{2}$, SHANGQI YANG ${ }^{1,2}$, \\ YAOTING GUI ${ }^{2}$, XIANGMING MAO ${ }^{1,2}$, YUN CHEN $^{5}$ and YONGQING LAI ${ }^{1,2}$ \\ ${ }^{1}$ Department of Urology, Peking University Shenzhen Hospital; ${ }^{2}$ The Guangdong and Shenzhen Key Laboratory \\ of Male Reproductive Medicine and Genetics, Peking University Shenzhen Hospital, Institute of Urology \\ of Shenzhen PKU-HKUST Medical Center, Shenzhen, Guangdong 518036; ${ }^{3}$ Anhui Medical University, \\ Hefei, Anhui 230032; ${ }^{4}$ Shantou University Medical College, Shantou, Guangdong 515041; ${ }^{5}$ Department of \\ Ultrasound Division, Peking University Shenzhen Hospital, Shenzhen, Guangdong 518036, P.R. China
}

Received May 16, 2015; Accepted September 9, 2015

DOI: $10.3892 / o r .2016 .4579$

\begin{abstract}
Renal cell carcinoma (RCC) is the most common kidney cancer in adults and has a poor prognosis. $c A M P$ responsive element binding protein $1(C R E B 1)$ is a proto-oncogenic transcription factor involved in malignancies of various organs. However, its functional role(s) have not yet been elucidated in RCC. We investigated the expression pattern, function and regulation of $C R E B 1$ in RCC. CREBI was overexpressed in the RCC tissues and cell lines. Downregulation of CREB1 inhibited RCC tumorigenesis by affecting cell proliferation, migration and apoptosis. Multiple computational algorithms predicted that the 3'-untranslated region (3'-UTR) of human CREB1 mRNA is a target for miR-10b-5p and miR-363-3p. Luciferase reporter assay, qPCR and western blot analysis confirmed that miR-10b-5p and miR-363-3p bind directly to the 3'-UTR of CREBI mRNA and inhibit mRNA and protein expression of $C R E B 1$. qPCR data also revealed a significantly lower expression of miR-10b-5p and miR-363-3p in RCC tissues. Introduction of miR-10b-5p and miR-363-3p mimics led to suppressed expression of $C R E B 1$ and inhibited
\end{abstract}

Correspondence to: Professor Yongqing Lai, Department of Urology, Peking University Shenzhen Hospital, Institute of Urology of Shenzhen PKU-HKUST Medical Center, 1120 Lianhua Road, Shenzhen, Guangdong 518036, P.R. China

E-mail: yqlord@163.com

Professor Yun Chen, Department of Ultrasound Division, Peking University Shenzhen Hospital, 1120 Lianhua Road, Shenzhen, Guangdong 518036, P.R. China

E-mail: cyun126@126.com

*Contributed equally

Key words: CREB1, miR-10b-5p, miR-363-3p, renal cell carcinoma, oncogene cell proliferation, migration and apoptosis reduction. Taken together, we propose that $C R E B 1$ is an oncogene in RCC and that upregulation of $C R E B 1$ by loss of tumor suppressive miR-10b-5p and miR-363-3p plays an important role in the tumorigenesis of RCC.

\section{Introduction}

Renal cancer is one of the 14 most frequent cancers worldwide and its incidence as well as mortality rate have plateaued in Western countries during the past decade. In developing countries, the incidence of tumors of the kidney has increased $(1,2)$. Renal cell carcinoma (RCC) is the most common renal cancer in adults. In the United States, the rate of RCC has increased by $1.7 \%$ per year for the past 10 years (3). In China, kidney cancer incidence has increased with an average annual growth rate of $6.5 \%$ in the past 20 years, and kidney cancer-related deaths have surpassed bladder cancer moving to the first place in cancers of the urinary system $(4,5)$. RCC has a poor prognosis due to a lack of early-warning signs and symptoms and resistance to radiotherapy and chemotherapy (6). Therefore, it is important to identify novel biomarkers for early detection, diagnosis and personalized therapy.

Transcription factors are key regulators of the pattern of gene expression and directly regulate biological processes such as cell growth, proliferation, survival, self-renewal and invasion. By driving the expression of key target genes, these oncogenic transcription factors play a central role in tumor pathogenesis (7). cAMP responsive element binding protein 1 (CREB1) is a proto-oncogenic transcription factor. Aberrent expression of $C R E B 1$ has been found in acute myeloid leukemia (AML) (8), non-small cell lung carcinoma (NCLC) (9), breast cancer (10), gliomas (11), mesotheliomas (12) and endocrine tumors $(13,14)$. As a potent oncogene, through gene amplification, chromosome translocation, interaction with viral oncoproteins and inactivation of tumor-suppressor genes (15), CREB1 promotes tumorigenesis by significantly impacting growth, prolifera- 
tion, survival, metastasis and invasion of tumor cells $(7,12)$. In response to various stimuli such as growth factors, neurotransmitters, stress signals and other agents that elevate intracellular $c A M P$ or $\mathrm{Ca}^{2+}$ levels, $C R E B$ is activated through phosphorylation at Ser133 and/or nuclear translocation of transducer of regulated $C R E B$ activity (TORC) coactivators (15). In addition, activated $C R E B 1$ turns on the transcription of more than 5,000 target genes such as c-fos (16), cell cycle regulatory genes such as cyclin A1 and cyclin D2 $(17,18)$, and other genes related to glucose homeostasis, growth factor-dependent cell survival and neuronal activities such as memory and learning (19-21). However, the oncogenic role of CREBI has not been investigated in RCC.

MicroRNAs (miRNAs) play important roles in many biological processes including tumorigenesis by regulating $\sim 50 \%$ of human protein-coding genes (22). Depending on their target genes, miRNAs can function as both oncogenes and tumor-suppressor genes by affecting cell differentiation, migration, growth, proliferation, apoptosis and metabolism (22-24). Generally, miRNAs, as a negative regulator, bind to a partially complementary sequence usually located in the 3'-untranslated region (3'-UTR) of their target mRNA and inhibit its translation (25). By targeting the most common genes involved in RCC tumorigenesis including the VHL/HIF, VEGF and $m T O R$ pathway, miRNAs play crucial roles in RCC initiation and development $(26,27)$.

In the present study, we showed that the cell proliferation, migration and apoptosis reduction of human RCC cell lines were suppressed by knockdown of $C R E B 1$. Furthermore, using computational prediction followed by experimental confirmation, miR-10b-5p and miR-363-3p were found to bind directly to the 3'-UTR of CREBI and downregulate $C R E B 1$. In human samples, miR-10b-5p and miR-363-3p expression was downregulated while $C R E B 1$ expression was upregulated, and a negative correlation was found between miR-10b-5p and miR-363-3p and CREB1 expression. Finally, the oncogenic activity of $C R E B 1$ was decreased by miR-10b-5p and miR-363-3p which showed a similar function to si-CREBI.

\section{Materials and methods}

Clinical specimens. A total of 35 paired fresh RCC specimens and adjacent normal tissues (ANTs) were collected from the Peking University Shenzhen Hospital (Shenzhen, Guangdong, China). All patients were informed in regards to the purposes of this research and provided written consent. This study was approved by the Institutional Review Board and Ethics Committee of Peking University Shenzhen Hospital, China. All the RCC samples were diagnosed as RCC pathologically without chemotherapy or radiotherapy before surgery, and the ANTs were collected from the normal region $\geq 5 \mathrm{~cm}$ outside the tumor range. All specimens were immediately frozen in liquid nitrogen following surgical resection for further study. The clinicopathological information of the patients is documented in Table I.

Cell culture and cell transfection. Human RCC cell lines, including 786-O, ACHN and Caki-2, and cervical cancer cell line HeLa were obtained from the American Type Culture
Table I. Clinicopathological features of the RCC patients.

\begin{tabular}{lc}
\hline Characteristics & Data \\
\hline Mean age (range), in years & $49(25-71)$ \\
Gender, no. of patients & $23 / 12$ \\
$\quad$ Male/female & \\
Histological type, no. of patients & $32 / 3$ \\
Clear cell/papillary & \\
pT-stage, no. of patients & $19 / 14 / 2$ \\
T1/T2/T3+T4 & $10 / 18 / 5 / 2$ \\
Fuhrman grade, no. of patients & \\
I/II/III/IV & $21 / 11 / 3$ \\
AJCC clinical stages, no. of patients & \\
I/II/III+IV &
\end{tabular}

cpT, primary tumor; AJCC, American Joint Committee on Cancer.

Collection (ATCC, Manassas, VA, USA). The human embryo kidney cell line 293T (293T) was purchased from the Type Culture Collection of the Chinese Academy of Medical Sciences, Beijing, China. All cell lines were cultured in Dulbecco's modified Eagle's medium (DMEM) (Gibco, Carlsbad, CA, USA), with $10 \%$ fetal bovine serum (Gibco), $1 \%$ antibiotics $(100 \mu \mathrm{g} / \mathrm{ml}$ penicillin and $100 \mathrm{mg} / \mathrm{ml}$ streptomycin sulfates) and $1 \%$ glutamate (Gibco), and then incubated at $37^{\circ} \mathrm{C}$ in a humidified chamber containing $5 \% \mathrm{CO}_{2}$.

For the downregulation of $C R E B 1$, two siRNAs targeting CREBI (si-CREBla and si-CREBIb) were designed and purchased from GenePharma (Shanghai, China). A negative control (NC) (siRNA-NC, si-NC), positive control (siRNA-GAPDH) and Fam-labeled siRNA-NC (siRNA-NC-FAM) used in this study were also designed and purchased from GenePharma. For the overexpression of miR-10b-5p and miR-363-3p, miR-10b-5p and miR-363-3p mimic oligoribonucleotides and NC were all chemically synthesized and purchased from GenePharma. When the cells reach $60-80 \%$ confluency, they were transfected with si-CREBla, si-CREBIb, si-NC, siRNA-GAPDH, siRNA-NC-FAM, miR-10b-5p and miR-363-3p mimics or the NC using Lipofectamine 2000 (Invitrogen, Carlsbad, CA, USA), which were mixed in Opti-MEM ${ }^{\circledR}$ I reduced serum medium (Gibco). Then, fluorescence microscopy and the quantitative real-time PCR (qPCR) were used to verify and quantify transfection efficiency. The sequences of all the siRNAs and RNAs are summarized in Table II.

$R N A$ extraction, reverse transcription and $q P C R$. The total RNA of cells and tissue samples was extracted using TRIzol reagent (Invitrogen) according to the manufacturer's protocol. The RNA samples with 260/280 ratios of 1.8-2.0 were used for further experiments. Total RNA was converted into cDNA by using the miScript II RT kit (Qiagen, Valencia, CA, USA) or PrimeScript ${ }^{\mathrm{TM}}$ RT reagent kit (Takara Bio, Inc., Otsu, Japan). qPCR analysis was used to detect the expression level of $C R E B 1$ using $\mathrm{SYBR}^{\circledR}$ Premix Ex Taq II (Takara) and the expression level of miR-10b-5p and 
Table II. Sequences of the primers, siRNAs and RNAs.

\begin{tabular}{lll}
\hline Name & & \multicolumn{2}{c}{ Sequence } \\
\hline CREB1 & F: 5'-GCCTGCTATACCTGCCATTG-3' & R: 5'-ACCCGATTCCGATTTGCTTAG-3' \\
GAPDH & F: 5'-GGAGCGAGATCCCTCCAAAAT-3' & R: 5'-GGCTGTTGTCATACTTCTCATGG-3' \\
si-CREB $1 a$ & F: 5'-GAGAGAGGUCCGUCUAAUG-3' & R: 5'-CAUUAGACGGACCUCUCUC-3' \\
si-CREB $1 b$ & F: 5'-AUUGUUAGCCAGCUGUAUUG-3' & R: 5'-CAAUACAGCUGGCUAACAAU-3' \\
siRNA- $N C$ & F: 5'-UUCUCCGAACGUGUCACGUTT-3' & R: 5'-ACGUGACACGUUCGGAGAATT-3' \\
siRNA-GAPDH & F: 5'-GUAUGACAACAGCCUCAAGTT-3' & R: 5'-CUUGAGGCUGUUGUCAUACTT-3' \\
siRNA- $N C$-FAM & F: 5'-UAUGUAGCUAACAAGGUGCCA-3' & R: 5'-UUCUCCGAACGUGUCACGUTT-3' \\
miR-10b-5p & F: 5'-TACCCTGTAGAACCGAATTTGG-3' & \\
miR-363-3p & F: 5'-AATTGCACGGTATCCATCTGTA-3' & \\
U6 & F: 5'-CTCGCTTCGGCAGCACA-3' & R: 5'-ACGCTTCACGAATTTGCGT-3' \\
miR-10b-5p mimics & F: 5'-UACCCUGUAGAACCGAAUUUGUG-3' & R:5'-CAAAUUCGGUUCUACAGGGUAUU-3' \\
miR-363-3p mimics & F: 5'-AAUUGCACGGUAUCCAUCUGUA-3 & R: 5'-CAGAUGGAUACCGUGCAAUUUU-3' \\
NC & F: 5'-UUCUCCGAACGUGUCACGUTT-3' & R: 5'-ACGUGACACGUUCGGAGAATT-3' \\
\hline
\end{tabular}

${ }^{a}$ The reverse primer was provided by the miScript SYBR ${ }^{\circledR}$-Green PCR kit (Qiagen, Valencia, CA, USA). F, forward; R, reverse.

miR-363-3p using miScript SYBR ${ }^{\circledR}$-Green PCR kit (Qiagen), respectively, according to the manufacturer's instructions on the LightCycler 480 real-time PCR system (Roche Applied Science, Mannheim, Germany). GAPDH and U6 were used as the internal control. Their expression levels were shown as fold differences relative to GAPDH and U6, which was based on the equation: Relative expression $=2^{-\Delta \Delta \mathrm{Ct}}, \Delta \Delta \mathrm{Ct}=$ $\left(\right.$ meanCt $_{\text {cancer }}-$ meanCt $\left._{\text {control }}\right)-\left(\right.$ meanCt $_{\text {normal }}-$ meanCt $\left._{\text {control }}\right)$. The primers used for this study are shown in Table II. All reactions were run in triplicate.

Cell proliferation assay. The 3-(4,5-dimethylthiazol-2-yl)-2, 5 -diphenyltetrazolium bromide assay (MTT, $5 \mathrm{mg} / \mathrm{ml}$; Sigma-Aldrich, St. Louis, MO, USA) was used to analyze the cell proliferation according to the manufacturer's protocol. Human RCC cells (786-O and ACHN) were seeded into 96-well culture plates at a cell density of 5,000 cells/well and transfected with either 13.3 pmol siRNAs or miRNAs for each well. Cell growth was assayed by addition of $20 \mu 1$ of MTT to each well, and the plate was incubated at $37^{\circ} \mathrm{C}$ for 4-6 h. Later, the reaction was stopped by addition of $120 \mu \mathrm{l}$ DMSO (Sigma-Aldrich). After shaking for $30 \mathrm{~min}$ at room temperature, the optical density (OD) at the wavelength of $490 \mathrm{~nm}$ (with $630 \mathrm{~nm}$ as the reference wave length) of each sample was measured with an enzyme immunoassay instrument (Bio-Rad, Hercules, CA, USA). The OD values were measured for 3 days at every $24 \mathrm{~h}$ interval. All assays were carried out in triplicate.

Cell migration assay. For the Transwell migration assays, $1 \times 10^{4} 786-\mathrm{O}$ or ACHN cells were harvested $24 \mathrm{~h}$ post-transfection. They were then plated into the upper chambers (24-well insert, pore size $8 \mu \mathrm{m}$; Corning, Inc., Corning, NY, USA) with $100 \mu \mathrm{l}$ serum-free DMEM. The lower chambers were filled with $500 \mu \mathrm{l}$ DMEM containing $10 \%$ fetal bovine serum. The cells were then cultured at $37^{\circ} \mathrm{C}$ in a humidified chamber containing $5 \% \mathrm{CO}_{2}$. Two days later, the cells on the surface of the upper chamber were wiped off with cotton gently. Cells under the surface of the lower chamber were washed with PBS, fixed with paraformaldehyde for $25 \mathrm{~min}$, stained with $0.1 \%$ crystal violet for $25 \mathrm{~min}$, and then washed with PBS tenderly three times.

Wound scratch assay was also used to examine the migration of RCC cells. Approximately $3 \times 10^{5} 786-\mathrm{O}$ or ACHN cells were seeded in 12-well plates one day before the transfection. The cells were transfected when they grew to reach $80-90 \%$ confluency, and a sterile $200-\mu 1$ pipette tip was used to scrape a clear line through the cell monolayer $6 \mathrm{~h}$ post-transfection. Then, the medium was changed with serum-free DMEM. Images of the scratches were acquired with a digital camera system at 0 and $24 \mathrm{~h}$. Experiments were run in three independent repeats in triplicate and analyzed in a double-blinded manner by at least two observers.

Cell apoptosis assay. For cell apoptosis analysis, $2 \times 10^{5} 786-\mathrm{O}$ or ACHN cells were seeded in 6-well plates and transfected with 200 pmol siRNAs/miRNAs for 6 h. Forty-eight hours post-transfection, the cells, including floating cells, were harvested, washed twice with $4^{\circ} \mathrm{C}$ PBS and resuspended in $100 \mu \mathrm{l} 1 \mathrm{X}$ binding buffer and stained with $5 \mu \mathrm{l}$ of propidium iodide (PI) and $5 \mu \mathrm{l}$ of Annexin V-FITC (Invitrogen) for 15 min at room temperature. Flow cytometry (EPICS, Xl-4; Beckman, CA, USA) was used to quantify the percentage of apoptotic cells within $30 \mathrm{~min}$ after staining and $400 \mu \mathrm{l} 1 \mathrm{X}$ binding buffer was added to each sample before measurement. Each experiment was conducted at least three times.

Target gene prediction. Prediction of miRNAs that target $C R E B 1$ was performed by computational algorithms due to their base-pairing rules between miRNA and mRNA target sites, location of binding sequences within the target's 3'-UTR, and conservation of target binding sequences within related 
genomes. In our study, miRNAs that target $C R E B 1$ were predicted by miRanda (http://mirdb.org/miRDB/index.html), TargetScan Release 6.2(http://www.targetscan.org),microRNA (http://www.microrna.org), and miRWalk (http://www.umm. uni-heidelberg.de/apps/zmf/mirwalk). Putative miRNAs targeting CREB1 predicted by all four algorithms were accepted and candidates were chosen based on experimental confirmation.

Plasmid construction and luciferase reporter assay. Luciferase reporter plasmids within the CREB1 3'-UTR fragment (500 bp) that containing target sequences of miR-10b-5p and miR-363-3p were constructed to confirm that miR-10b-5p and miR-363-3p bind directly to the 3'-UTR of CREB1 and inhibit its translation. The miRNA target sequences were inserted between the XhoI-NotI restriction sites in the 3'-UTR of the $h R l u c$ gene in the psiCHECK ${ }^{\mathrm{TM}}-2$ luciferase vector (Promega, Madison, WI, USA), generating the wild-type (WT) of psiCHECK ${ }^{\mathrm{TM}}-2-3$ 'UTR. The primer sequences for the 3'-UTR of CREB1 mRNA containing the miR-10b-5p binding site (forward primer, 5'-CCGCTCGAGTGAAGAGTTGTGAGA TAAATAGTTC-3' and reverse primer, 5'-AAGGAAAAAAG CGGCCGCCCTGTTTATAATATCAACTTGCATC-3') and containing the miR-363-3p binding site (forward primer, 5'-CCGCTCGAGCTCAAGAAATTTTCAACGCCAG-3' and reverse primer, 5'-AAGGAAAAAAGCGGCCGCGTTGAA CACATACAGAACTGAATTA-3') were designed. Then, we mutated the potential binding sites by exchanging the $\mathrm{G}$ and $\mathrm{T}$, $A$ and $C$, and inserted the mutated sequences in psiCHECK тм -2-3'UTR (MUT) (Fig. 6A and C). These short fragments were all cloned into psiCHECK-2 luciferase vector, respectively, and all the constructs were verified by sequencing.

For the luciferase reporter assay, $0.2 \mu \mathrm{g}$ luciferase reporter vectors, together with 20 pmol miR-10b-5p mimics, miR-363-3p mimics and negative control, were transfected into 786-O, ACHN, HeLa and 293T cells using Lipofectamine 2000. Luciferase activity was detected using the dual luciferase assay system (Promega) on the Modulus ${ }^{\mathrm{TM}}$ Single Tube Multimode Reader (Bio-Systems International, Beloit, WI, USA), according to the manufacturer's instructions $24 \mathrm{~h}$ after transfection. Normalized data were calculated as the quotient of Renilla/Firefly luciferase activities. The experiments were performed in duplicate and repeated at least three times.

Immunohistochemistry (IHC). Immunohistochemical assay of $C R E B 1$ was performed in $20 \mathrm{RCC}$ paraffin-embedded tissues according to standard procedures. The $5-\mu \mathrm{m}$ sections were dewaxed in xylene, rehydrated in a descending series of ethanol, incubated in 3\% hydrogen peroxide solution for $20 \mathrm{~min}$, boiled in $0.01 \mathrm{M}$ citrate buffer ( $\mathrm{pH}$ 6.0) for antigen retrieval, and treated in $10 \%$ bovine serum albumin for $30 \mathrm{~min}$ at $37^{\circ} \mathrm{C}$ to block non-specific protein binding. Then the sections were incubated in CREBI mouse monoclonal antibody (1:100, ab178322; Cambridge, MA, USA) overnight at $4^{\circ} \mathrm{C}$. Subsequently, the sections were rinsed with PBS and treated with the anti-rabbit IHC kit (Maixin Bio, Fuzhou, China) at $37^{\circ} \mathrm{C}$ for $30 \mathrm{~min}$, followed by staining with a DAB kit (Maixin Bio), for $4 \mathrm{~min}$ and counterstained with hematoxylin. Negative controls were performed with omission of the primary antibodies.
Protein extraction and western blot analysis. The frozen fresh samples and collected cells of human RCC cell lines (786-O and ACHN) seeded in a 6-well plate were homogenized in three volumes of RIPA buffer (Sigma-Aldrich) on ice. The protein concentration was quantified using Pierce BCA protein assay kit (Thermo Scientific, Waltham, MA, USA), and protein samples $(60 \mu \mathrm{g})$ were separated by $10 \%$ SDS-PAGE and transferred onto polyvinylidene fluoride membranes (Millipore, Billerica, MA, USA). After blocking with $5 \%$ fat-free milk at room temperature for $2 \mathrm{~h}$, the membranes were incubated in 5\% fat-free milk containing CREB1 (1:100, ab178322; Abcam) or $\beta$-actin $(1: 5,000$, NB600-532; Novus, Littleton, CO, USA) antibody overnight at $4^{\circ} \mathrm{C}$. The membranes were washed three times with TBST (Tris-buffered saline with $0.05 \%$ Tween) and incubated for $1 \mathrm{~h}$ with horseradish peroxidase (HRP)-linked secondary antibody $(1: 10,000$; EarthOx, LLC, USA) at room temperature. The protein bands were detected with the chemiluminescence phototube-HRP kit (WBKLS0500; Millipore) and exposure to Kodak film.

Statistical analysis. All data are expressed as the mean \pm SD from at least three separate experiments. All data were analyzed by SPSS 19.0 statistical software (SPSS Inc., Chicago, IL, USA). The clinicopathological information of the patients was analyzed by Chi-square test, while other data were determined by the Student's t-test. Results were considered statistically significant with two-tailed $\mathrm{P}<0.05$.

\section{Results}

Validation of the upregulation of CREBI in the RCC tissues and cell lines by $q P C R$. To determine the mRNA expression level of $C R E B 1$, qPCR was performed in 35 paired RCC tissues and ANTs. As shown in Fig. 1A, the expression of CREB1 was significantly upregulated in the RCC tissues compared with ANTs. We also analyzed the expression of CREB1 in RCC cell lines (786-O, ACHN and Caki-2) and 293T. As shown in Fig. 1B, the expression level of CREBl was significantly higher in the ACHN, 786-O and Caki-2 cells $(\mathrm{P}<0.01)$ compared with the level in the $293 \mathrm{~T}$ cells.

Protein expression of CREBI in the RCC tissues and ANTs. CREBI was discovered to be upregulated in many human cancers including leukemia (8), breast cancer (10), gliomas (11) and lung cancer (9). However, the protein expression of $C R E B 1$ in renal cancer remains unknown. Therefore, we performed IHC and western blot analysis to determine the protein expression of CREBI in 20 pairs of RCC sections and 6 pairs of fresh tissues, respectively. The results of the IHC assay showed that $C R E B I$ was located in the nuclei of the cells and overexpression of $C R E B 1$ was observed in $80 \%(16 / 20)$ of the RCC sections (Fig. 1C). The western blot assay also showed that $C R E B I$ was upregulated in all paired RCC tissues and human RCC cell lines (786-O and ACHN) compared with the ANTs and the 293T cell line, with $\beta$-actin as the internal control (Fig. 1D and E). No relationship was found between the protein expression level of $C R E B 1$ and clinicopathologic variables due to the limited number of cases. 
A

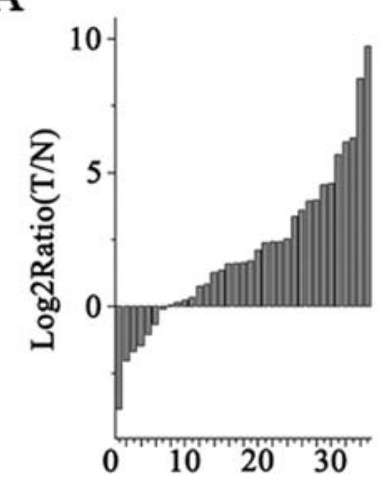

C

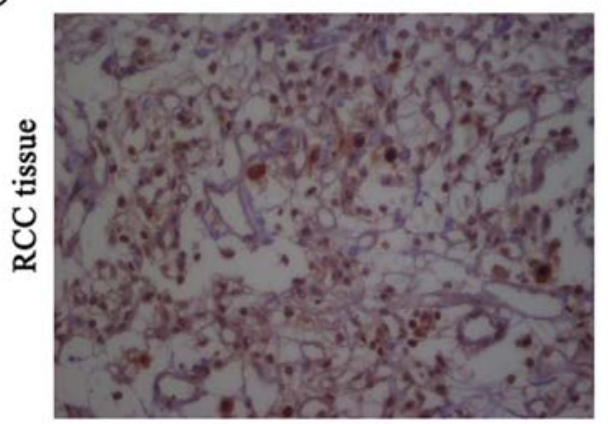

B

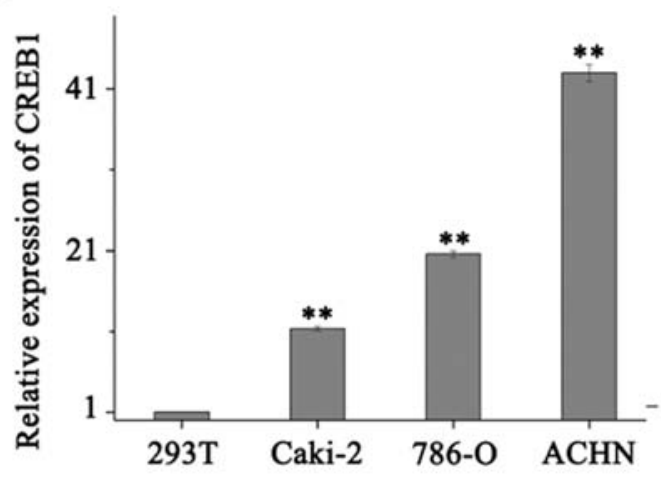

D

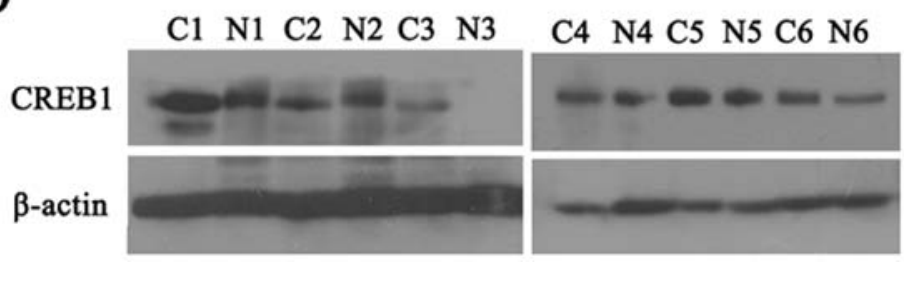

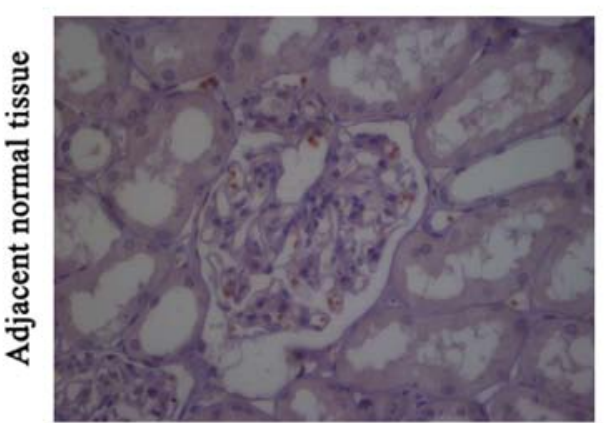

E

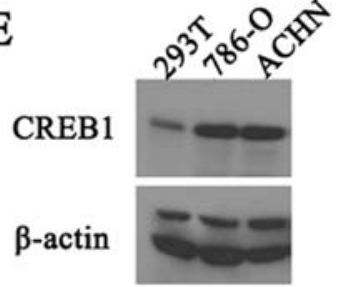

Figure 1. Overexpression of $C R E B 1$ in RCC tissues and cell lines. The mRNA expression of $C R E B 1$ in 35 paired RCC tissues and adjacent normal tissues (A) and human RCC cell lines (786-O, ACHN and Caki-2) and the 293T cell line (B). The protein expression of $C R E B 1$ in paired RCC and adjacent normal tissues as shown by immunohistochemistry (C) and western blot analysis (D); and the protein expression of $C R E B 1$ in human RCC cell lines (786-O and ACHN) and the $293 \mathrm{~T}$ cell line $(\mathrm{E}) .{ }^{* *} \mathrm{P}<0.01$.

Silencing of CREB1 inhibits cell proliferation and migration and induces cell apoptosis in vitro. To explore the function of $C R E B 1$ in renal cancer, two siRNAs to downregulate $C R E B I$ were designed and confirmed. Through transient transfection efficiency validation of the siRNAs (Fig. 2), we verified and chose si-CREBla as the most effective siRNA targeting $C R E B 1$. Cell proliferation, migration and apoptosis of 786-O and ACHN cells were evaluated after transfection with si-CREBla (si-CREB1) by MTT assay, Transwell migration assay, wound scratch assay and flow cytometry.

The results of the MTT assay revealed that downregulation of $C R E B 1$ suppressed cell proliferation. As shown in Fig. 3A, the cell proliferation of 786-O and ACHN cells was reduced by $8.15 \%(\mathrm{P}<0.05), 16.20 \%(\mathrm{P}<0.01), 32.51 \%(\mathrm{P}<0.01)$ and 9.51\% $(\mathrm{P}<0.05), 22.12 \%(\mathrm{P}<0.01), 31.41 \%(\mathrm{P}<0.05)$, respectively, after transfection of si-CREBl at 24,48 and $72 \mathrm{~h}$, compared with the cells transfected with si-NC, respectively. Transwell migration and wound scratch assays showed the same result. Inhibition of $C R E B 1$ attenuated the migratory ability of 786-O and ACHN cells. Transwell migration assay showed that the number of migrated cells was decreased by $89.98 \%(\mathrm{P}<0.01)$ in the $786-\mathrm{O}$ cells and by $90.57 \%(\mathrm{P}<0.01)$ in the ACHN cells (Fig. 3B). Wound scratch assay showed that the inhibition rate of migration was $40.07 \%$ for the $786-\mathrm{O}$ cells $(\mathrm{P}<0.01)$ and $49.61 \%$ for the ACHN cells $(\mathrm{P}<0.001)$ (Fig. 3C). Compared with the cells transfected with si-NC, the average cell apoptosis rate was increased significantly in the cells transfected with si-CREB1, with 6.36 vs. $10.09 \%$ in the $786-\mathrm{O}$ cells $(\mathrm{P}<0.05)$ and 6.16 vs. $12.88 \%$ in the ACHN cells $(\mathrm{P}<0.01)$ (Fig. 3D). All the data suggest that $C R E B 1$ is an oncogene and affects cellular proliferation, migration and apoptosis.

CREB1 is targeted by miR-10b-5p and miR-363-3p. Bioinformatic analyses (miRanda, TargetScan Release 6.2, microRNA and miRWalk) were used to determine the potential miRNAs that target CREB1. miR-10b-5p and miR-363-3p, were predicted by all four algorithms simultaneously and were selected as candidates for further study (Fig. 4A and B). Furthermore, miR-10b-5p and miR-363-3p were previously found to be downregulated in RCC tissues compared with ANTs or downregulated in metastatic compared with primary RCCs by all the high-throughput screens (28-33). 
A

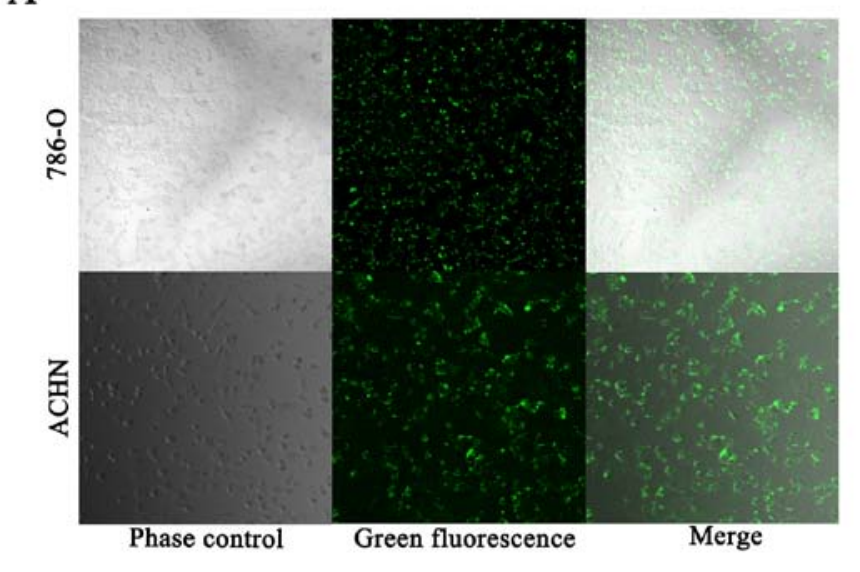

C

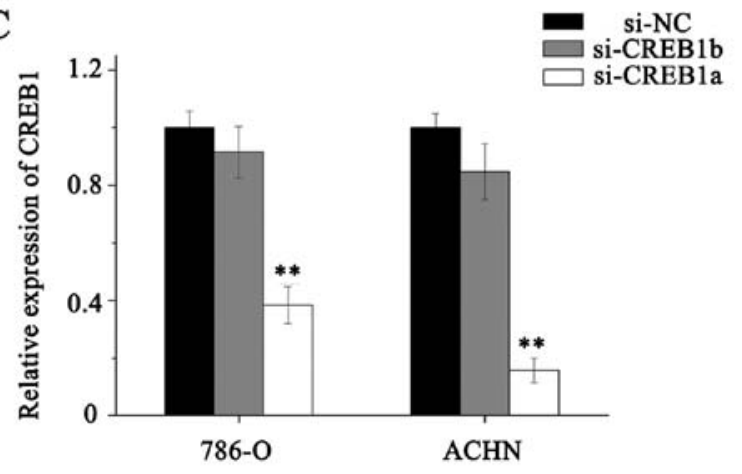

B
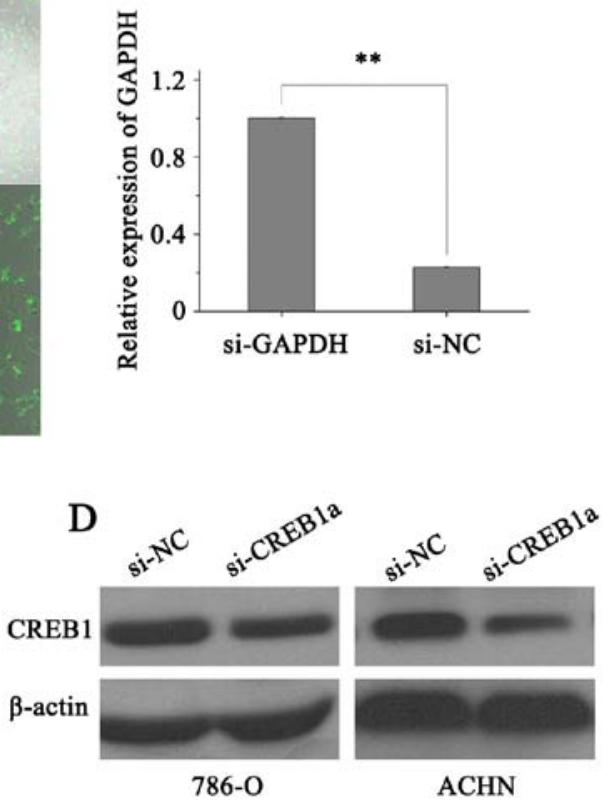

Figure 2. Validation of the silencing efficiency of $C R E B 1$. (A) Phase-contrast and green fluorescence images were captured from the same field. (B) The positive control of si-GAPDH was performed to guarantee the efficiency of the systemic experiments. (C) The relative expression of $C R E B 1 \mathrm{mRNA}$ in 786-O and ACHN cells transfected with si-CREBIa, si-CREBIb or si-NC. (D) The protein expression of CREB1 in 786-O and ACHN cells transfected with si-CREBIa or si-NC. ${ }^{* *} \mathrm{P}<0.01$.
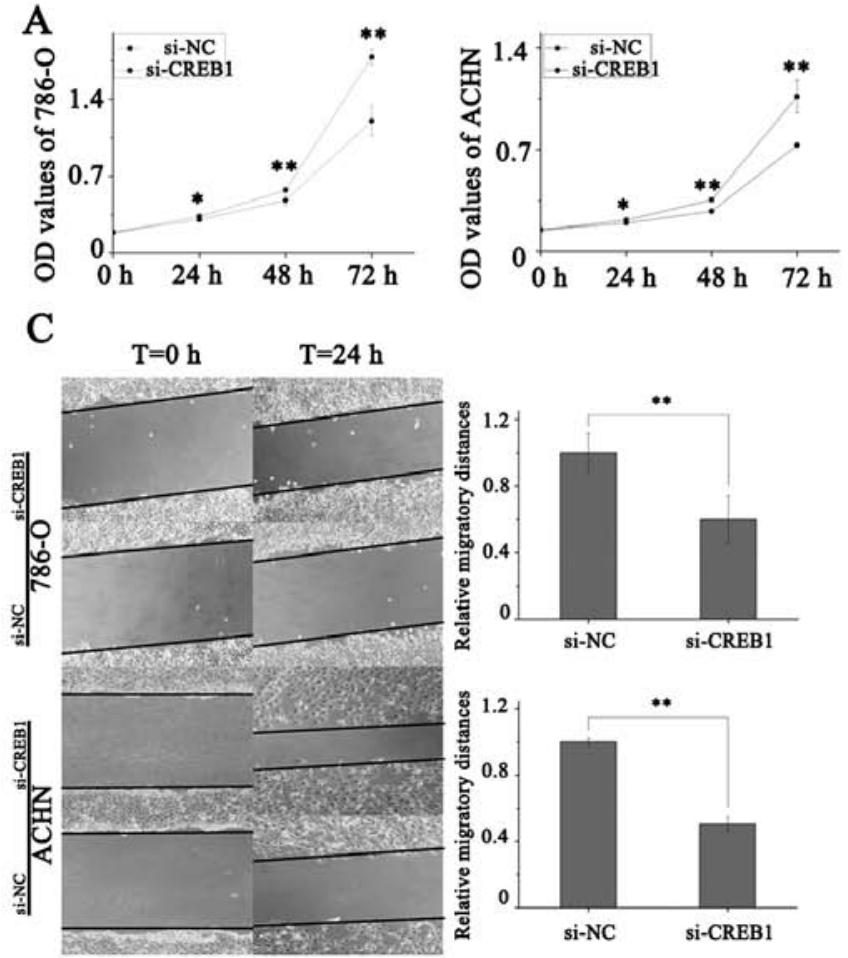

B

D
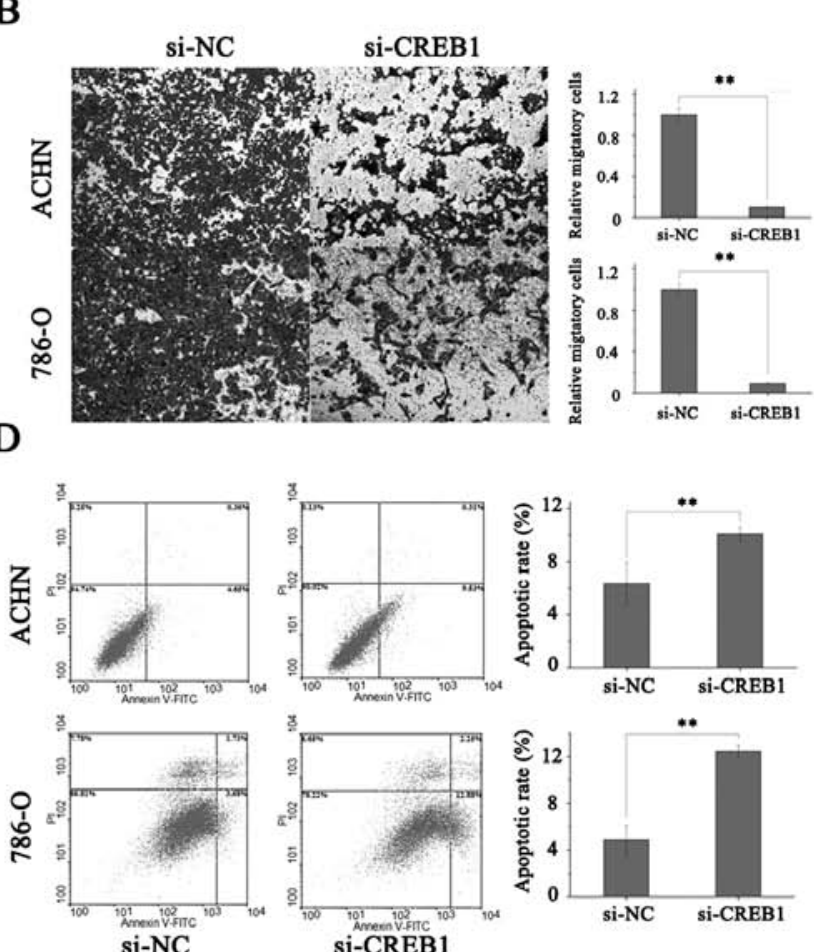

Figure 3. si-CREB1 inhibits neoplastic phenotypes of 786-O and ACHN cells. After introduction of si-CREB1 or si-NC, cell proliferation was measured by MTT assay (A), and cell migration was evaluated by Transwell migration (B) and wound scratch assays (C), and cell apoptosis was quantified by flow cytometry (D). ${ }^{*} \mathrm{P}<0.05,{ }^{* *} \mathrm{P}<0.01$. 
A

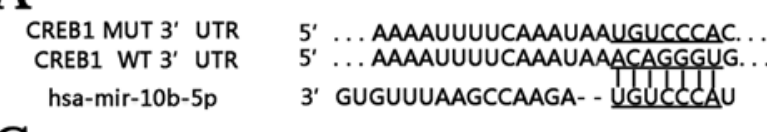

C
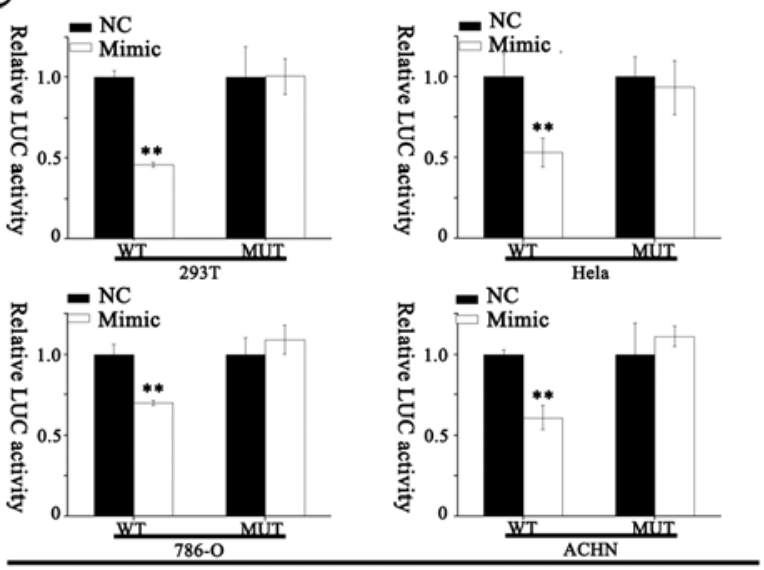

MiR-10b-5p

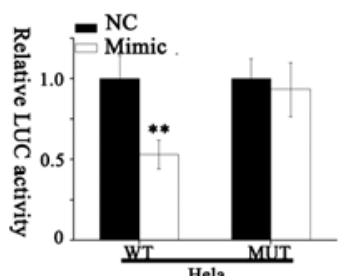

B

CREB1 MUT 3' UTR

CREB1 WT 3' UTR

hsa-mir-363-3p

D
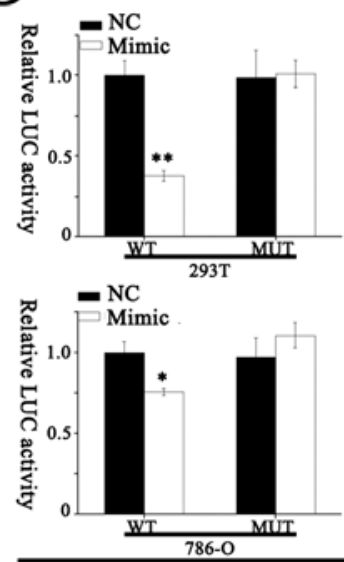

5' ... CAUAAAGUAAGCACGUUAG. .

5' ... CAUAAAGUAAGGUGCAAUG. .

3' AUGUCUACCUAUGGCACGUUJAA

MiR-363-3p
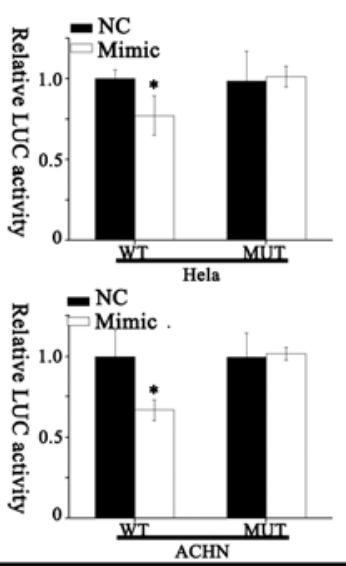

$\mathrm{ACHN}$

Figure 4. miR-10b-5p and miR-363-3p target CREB1. (A and B) Four fragments of CREB1 3'-UTR were constructed, which contained the wild-type (WT) potential binding sites of miR-10b-5p and miR-363-3p and the corresponding mutated sequence (MUT). (C and D) The psiCHECK ${ }^{\mathrm{TM}}-2$ luciferase constructs containing WT or MUT sequence were transfected together with miR-10b-5p, miR-363-3p mimics and NC into 786-O and ACHN cells. Luciferase activity was measured by the dual luciferase assay system. ${ }^{*} \mathrm{P}<0.05,{ }^{* *} \mathrm{P}<0.01$.

To determine whether $C R E B 1$ is directly regulated by miR-10b-5p and miR-363-3p, a luciferase reporter assay was performed in 293T, HeLa, 786-O and ACHN cells. As shown in Fig. 4C, the relative luciferase activity of wild-type plasmids containing the putative binding site was significantly decreased when transfected with miR-10b-5p mimics in the 293T ( $\mathrm{P}=0.001)$, HeLa $(\mathrm{P}=0.005), 786-\mathrm{O}(\mathrm{P}=0.009)$ and $\mathrm{ACHN}$ cells $(\mathrm{P}=0.006)$ while no notable reduction was observed in the mutant groups. As shown in Fig. 4D, when transfected with the miR-363-3p mimics, identical results were also obtained in the 293T $(\mathrm{P}=0.004), \mathrm{HeLa}(\mathrm{P}<0.05)$, 786-O $(\mathrm{P}<0.05)$ and $\mathrm{ACHN}$ cells $(\mathrm{P}<0.05)$, suggesting that miR-10b-5p and miR-363-3p may suppress the expression of CREBl by targeting the putative binding site in the 3'-UTR.

CREB1 is downregulated by miR-10b-5p and miR-363-3p in RCC cell lines and tissues. To validate the results of the luciferase reporter assay, we performed qPCR and western blot analysis to quantify the mRNA and protein levels of CREBI in the 786-O and ACHN cells $48 \mathrm{~h}$ after transfection with miR-10b-5p and miR-363-3p mimics. miR-10b-5p and miR-363-3p mimics significantly downregulated the mRNA and protein levels of CREBI (Fig. 5A and B). To further explore the relationship of the expression pattern between $C R E B 1$ and miR-10b-5p and miR-363-3p, we quantified the expression levels of miR-10b-5p and miR-363-3p in the 35 paired RCC tissues and ANTs by qPCR. We analyzed the fold-change, Log2Ratio(T/N), of CREBI and miR-10b-5p and miR-363-3p in each paired RCC tissue and ANT and we found that the expression level of CREBI decreased when miR-10b-5p and miR-363-3p expression increased, suggesting that CREBI was properly regulated by miR-10b-5p and miR-363-3p in the tissue samples (Fig. 5C). As shown in Fig. 6A and B, the results also showed that miR-10b-5p and miR-363-3p expression levels were significantly lower in the RCC tissues than the levels in the ANTs, respectively.

Introduction of miR-10b-5p and miR-363-3p suppresses cell proliferation, migration and apoptosis. To further confirm that lower expression levels of miR-10b-5p and miR-363-3p mediate the upregulation of CREBI to promote tumorigenicity, we introduced exogenous miR-10b-5p and miR-363-3p into human RCC cell lines (786-O and ACHN) and performed MTT and cell migration assays and apoptosis analysis. Forty-eight hours after transfection, the transient transfection efficiency was verified by qPCR (Fig. 7). Then MTT assay showed that overexpression of miR-10b-5p significantly decreased the cell proliferation of 786-O cells by $3.72 \%$ $(\mathrm{P}<0.05), 13.99 \%(\mathrm{P}<0.01), 16.75 \%(\mathrm{P}<0.01)$ and $\mathrm{ACHN}$ cells by $16.86 \%(\mathrm{P}<0.05), 18.16 \%(\mathrm{P}<0.01), 32.19 \%(\mathrm{P}<0.01)$, at 24 , 48 and $72 \mathrm{~h}$ post-transfection, respectively (Fig. 8A). Transwell migration assay found that the number of migratory cells was suppressed by $45.65 \%(\mathrm{P}<0.05)$ and $56.28 \%(\mathrm{P}<0.05)($ Fig. 8B) and the migratory distances were inhibited by $28.73 \%$ $(\mathrm{P}<0.05)$ and $30.97 \%(\mathrm{P}<0.01)$ (Fig. 8C) for 786-O and ACHN cells, respectively, after transfection of miR-10b-5p mimics. For the apoptosis assay, upregulated expression of miR-10b-5p promoted the mean early apoptotic rate from 4.77 to $13.20 \%$ $(\mathrm{P}<0.05)$ for $786-\mathrm{O}$ cells and from 10.31 to $24.04 \%(\mathrm{P}<0.05)$ for ACHN cells (Fig. 8D).

The proliferation ability of the 786-O and ACHN cells was attenuated identically by $6.70 \%(\mathrm{P}<0.05), 13.22 \%(\mathrm{P}<0.01)$, $19.79 \%(\mathrm{P}<0.01)$ and $10.53 \%(\mathrm{P}<0.05), 15.17 \%(\mathrm{P}<0.01)$, $24.14 \%(\mathrm{P}<0.01)$ due to introduction of miR-363-3p, respectively (Fig. 9A). After transfection of miR-363-3p mimics, for 786-O and ACHN cells, respectively, the migratory cells were 
A
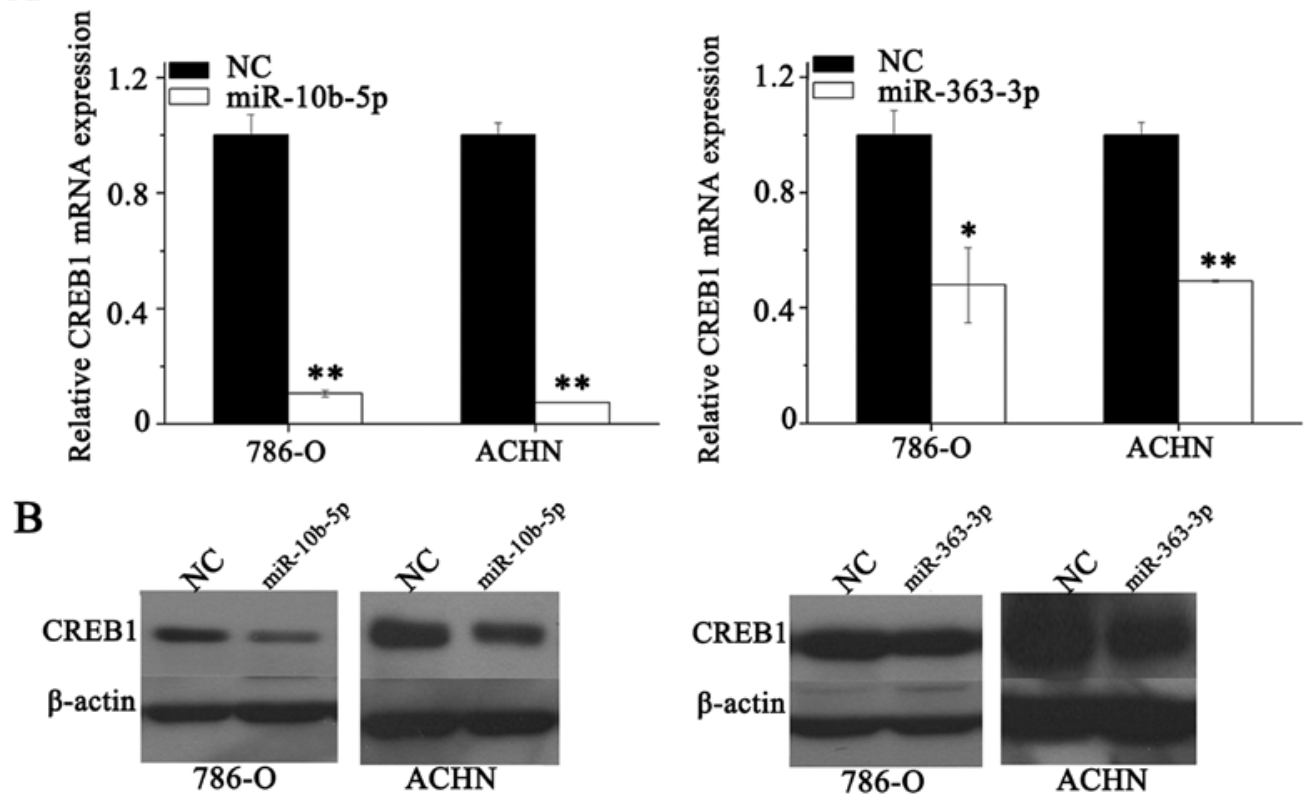

C
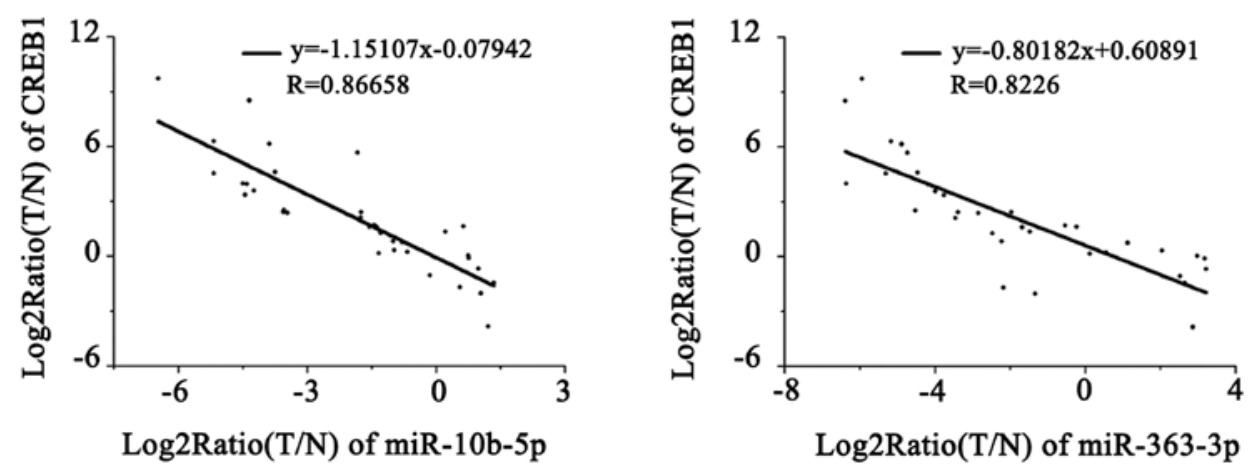

Figure 5. miR-10b-5p and miR-363-3p downregulate the expression of CREB1. (A and B) qPCR and western blot analysis indicate the effect of miR-10b-5p and miR-363-3p on CREBI expression at the mRNA and protein levels in 786-O and ACHN cells after transfection of miR-10b-5p mimics, miR-363-3p mimics and NC. (C) The mRNA expression level of CREB1 was negatively correlated with miR-10b-5p and miR-363-3p in the 35 paired RCC tissues and ANTs by qRT-PCR. Relative expression, $\log 2$ Ratio $(\mathrm{T} / \mathrm{N})$, method was used to analyze the data. ${ }^{*} \mathrm{P}<0.05,{ }^{* *} \mathrm{P}<0.01$.
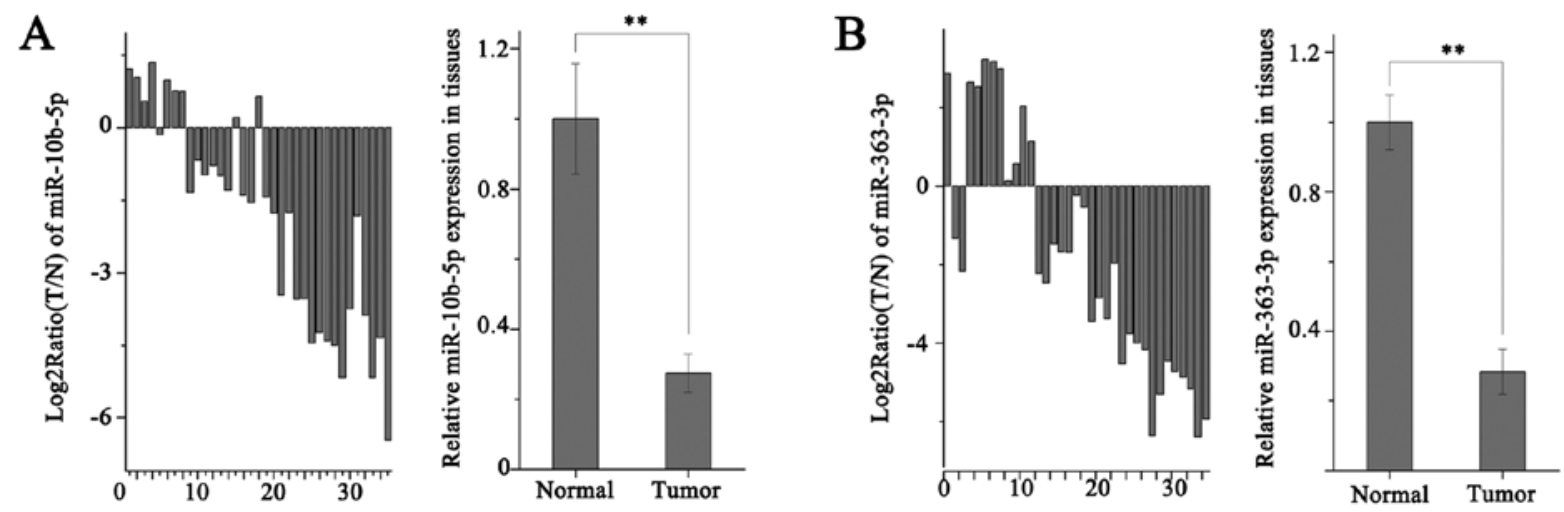

Figure 6. miR-10b-5p and miR-363-3p are downregulated significantly in RCC tissues. qPCR of miR-10b-5p (A) and miR-363-3p (B) expression relative to U6 expression in the 35 paired RCC tumor samples and ANTs. ${ }^{* *} \mathrm{P}<0.01$.

suppressed by $17.95 \%(\mathrm{P}<0.05)$ and $25.65 \%(\mathrm{P}<0.05)($ Fig. 9B) and the migratory distances were inhibited by $16.17 \%(\mathrm{P}<0.05)$ and $30.02 \%(\mathrm{P}<0.01)($ Fig. 9C) due to ectopic expression of
miR-363-3p. miR-363-3p mimics induced the mean early apoptotic rate from 4.56 to $9.58 \%(\mathrm{P}<0.05)$ for $786-\mathrm{O}$ cells and from 11.61 to $18.84 \%(\mathrm{P}<0.01)$ for ACHN cells (Fig. 9D). 
A

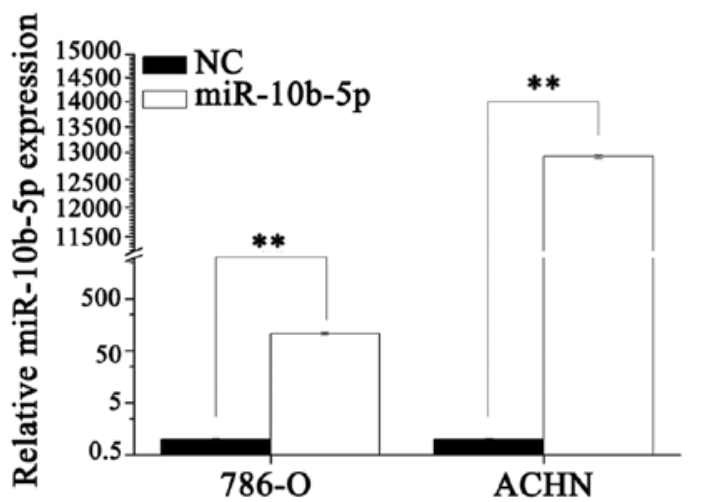

B

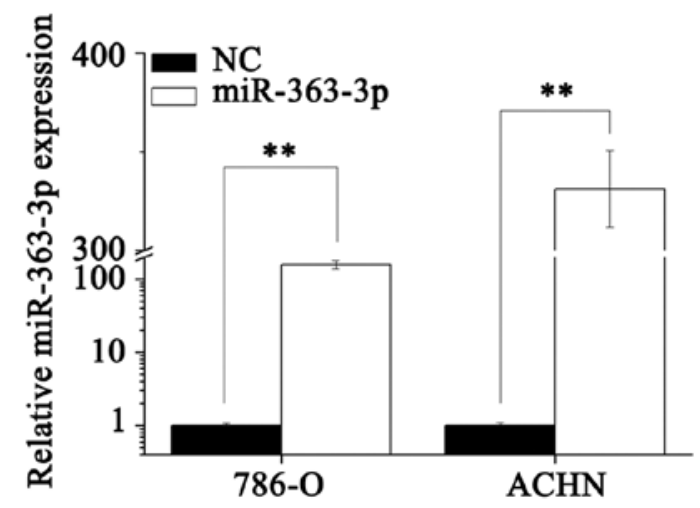

Figure 7. Validation of the upregulation of miR-10b-5p and miR-363-3p. The relative expression levels of miR-10b-5p (A) and miR-363-3p (B) in 786-O and ACHN cells transfected with miR-10b-5p mimic, miR-363-3p mimics or $\mathrm{NC}$. ${ }^{* *} \mathrm{P}<0.01$.

A

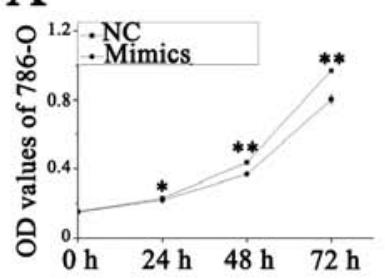

C
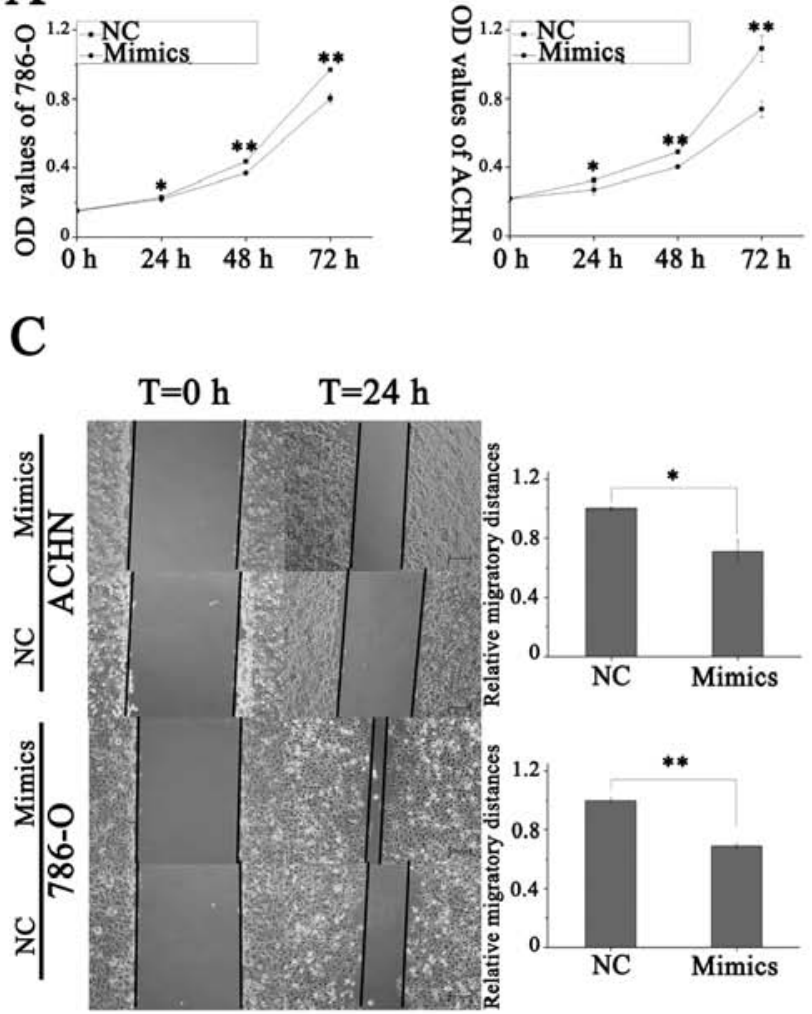

B
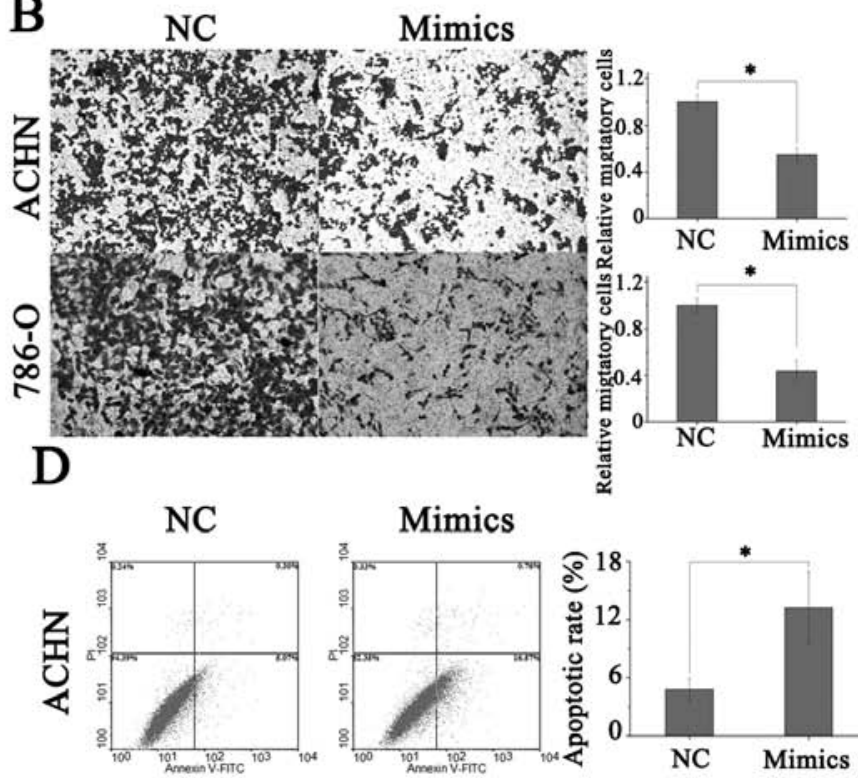

Mimics
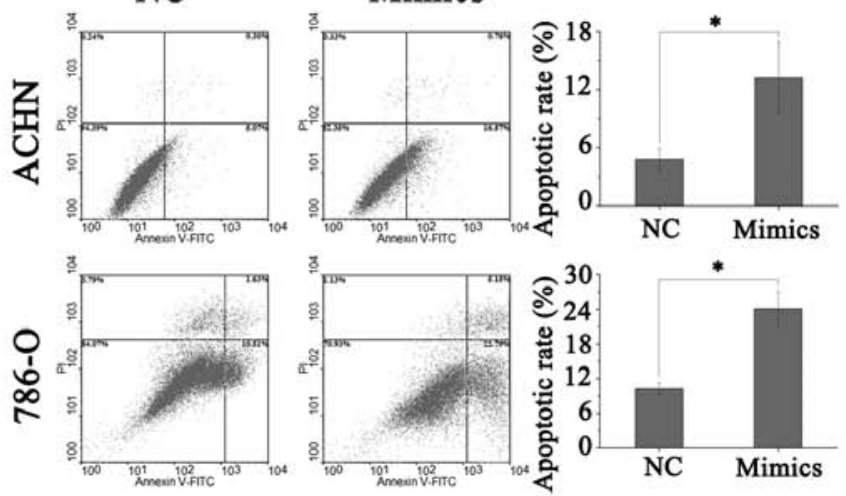

Figure 8. miR-10b-5p mimics suppress the proliferation, migration and apoptosis reduction in the RCC cell lines. MTT assay (A), Transwell migration assay (B), wound scratch assay (C) and cell apoptosis assay (D) were performed to examine proliferation, migration and apoptosis of the the 786-O and ACHN cells after transfection with miR-10b-5p mimics and NC. ${ }^{*} \mathrm{P}<0.05,{ }^{* *} \mathrm{P}<0.01$.

All the above data revealed that miR-10b-5p and miR-363-3p mimics exert a function similar to si-CREB1 by inhibiting cell proliferation and migration and inducing cell apoptosis, suggesting that low miR-10b-5p and miR-363-3p expression-mediated upregulation of CREBI in RCC tissues and cell lines restores tumorigenicity.

\section{Discussion}

The CREBI gene is localized at human chromosome 2q32.3-q34, a region known to be a hot spot for translocations or deletions in various diseases including carcinomas (34). Chromosomal translocations or deletions frequently result in the activation of cellular oncogenes, such as oncogene $c-M Y C$ in human B cell and plasma cell neoplasms (35). In the present study, we showed that CREBI expression was upregulated in human RCC cell lines and RCC tissues at the mRNA and protein levels.

To further determine the roles of CREBI in RCC development, we performed MTT and cell migration assays and cell apoptosis analysis after knockdown of $C R E B 1$. The results revealed that downregulation of $C R E B I$ expression resulted 

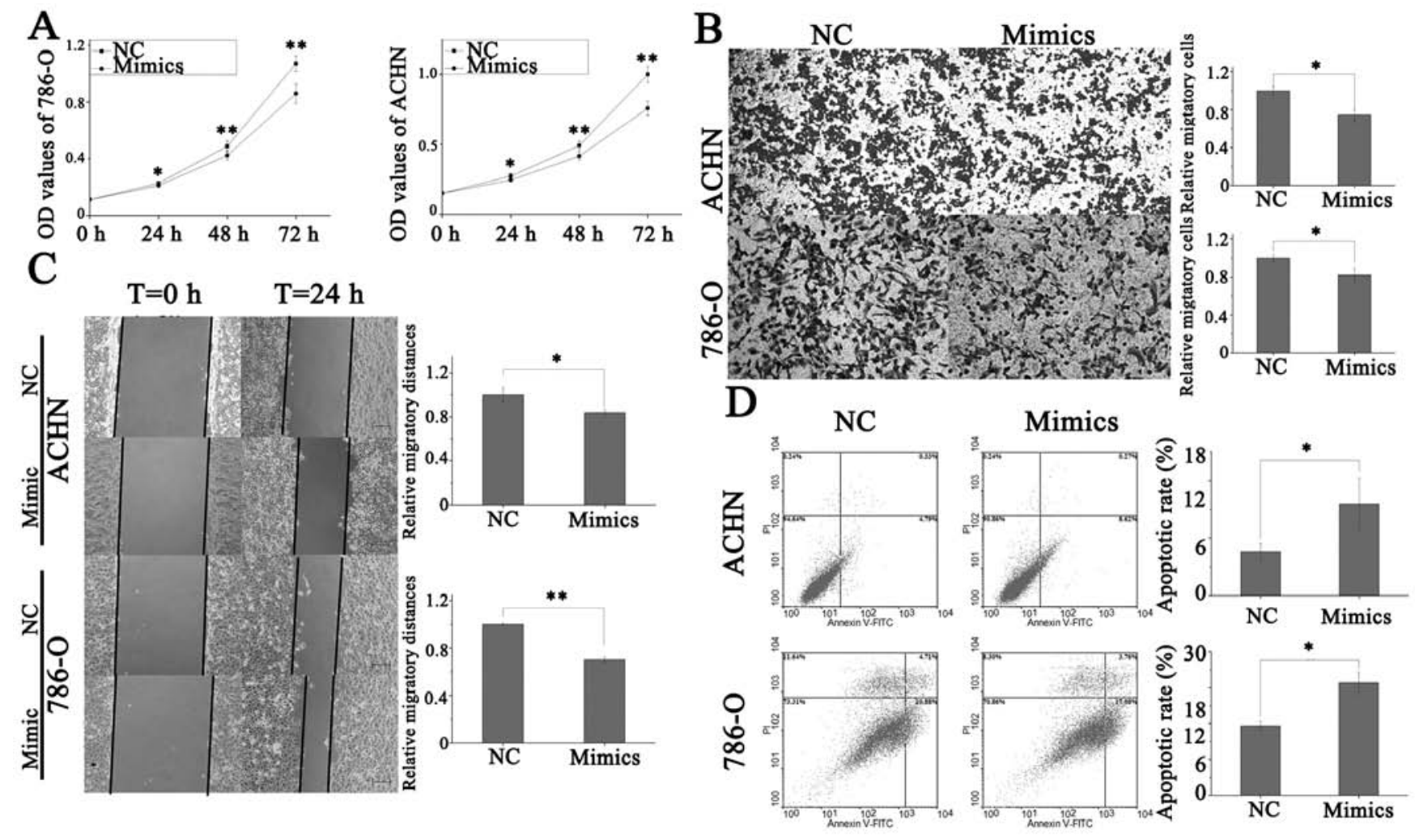

Figure 9. Effects of miR-363-3p mimics on RCC neoplastic phenotypes. MTT assay (A), Transwell migration assay (B), wound scratch assay (C) and cell apoptosis analysis (D) were performed to examine the proliferation, migration and apoptosis of the 786-O and ACHN cell after transfection with the miR-363-3p mimics and $\mathrm{NC}$. ${ }^{*} \mathrm{P}<0.05,{ }^{* *} \mathrm{P}<0.01$.

in the suppression of neoplastic phenotypes of RCC cells. It has been reported that overexpression of $C R E B 1$ promotes the growth and survival of myeloid and glioma cells $(8,36)$. CREBI is critical in intercellular adhesion molecule-3 (ICAM-3)induced cellular radioresistance and cancer cell proliferation in NSCLC cell lines (9). It has also been confirmed that CREBI binds to the promoter region and causes overexpression of LAPTM4B and is involved in the occurrence and progression of breast cancer (10). In the present study, we showed for the first time that inhibition of CREBI strongly suppressed the tumorigenic activity including proliferation, migration and apoptosis of RCC cells.

Oncogenes are activated by overexpression or inhibition of degradation at the mRNA and protein levels to promote tumor development. In leukemia, $C R E B$ gene copies were amplified through an unknown mechanism (8). In clear cell sarcoma (37), angiomatoid fibrous histiocytoma (38) and mucoepidermoid carcinoma (39), fusion oncoproteins comprising $C R E B$ or $A T F 1$ activated the expression of $C R E B$-regulated genes. In adult $\mathrm{T}$ cell leukemia and liver cancer, viral oncoproteins Tax of $H T L V-I$ and $H B x$ of hepatitis B virus physically interact with and activate $C R E B$ by enhancing DNA binding and/or coactivator recruitment (40-43). Inactivating mutations of tumor-suppressor gene, $L K B 1$ in Peutz-Jeghers syndrome and PDE11A in adrenocortical hyperplasia, induce the activation of CREB $(13,44)$. Therefore, the CREBI upregulation in RCC may be caused by different mechanisms.

Previous studies have reported that many tumor-suppressive miRNAs inhibit tumorigenesis by targeting CREBI in various types of cancers (45-50). CREB1 is targeted and downregulated by miR-9, miR-1224-5p and miR-200b in gliomas $(47,50,51)$. Oncogenic CREBI is also regulated negatively by tumor suppressive miR-181b and miR-182 in gastric cancer $(45,46)$ and targeted by miR-433 in liver cancer (49). In AML, miR-34b downregulation was shown to induce CREB overexpression, thereby causing leukemia proliferation in vitro, in vivo and in the clinic $(48,52)$. However, the relationship between CREB1 and miRNAs remains unknown in RCC. Multiple computational algorithms were used to search for miRNAs predicted to suppress CREBI expression. We identified the seed region matched between miR-10b-5p and miR-363-3p and the 3'-UTR of the $C R E B 1$ gene. Luciferase reporter assays confirmed that miR-10b-5p and miR-363-3p target CREB1 directly. Moreover, ectopic expression of miR-10b-5p and miR-363-3p suppressed CREB1 expression, thereby inhibted cell proliferation, migration and apoptosis reduction. Thus, a low level of miR-10b-5p and miR-363-3p is supportive for RCC tumorigenesis by way of loss of CREBI downregulation.

miR-10b-5p and miR-363-3p have been found dysregulated and to function in various cancers, especially in RCC. In RCC, 4 previous microarray profiling assays showed that miR-10b-5p was downregulated significantly in RCC tissues and metastic RCC tissues compared with normal kidney tissues and primary RCC tissues (29-32,53,54). miR-363-3p is part of the miR-29a family and is highly conservative in the process of evolution (55). Previous studies revealed that inhibition of miR-363-3p mediated invasion and metastasis of head and neck cancer by inducing podoplanin (56), promoted 
proliferation and G1 to $\mathrm{S}$ progression of hepatocellular cancer by targeting $S 1 P R 1$ and $c-M Y C(57,58)$. In RCC, miR-363-3p was reported to be significantly downregulated by microarray chip studies $(28,33)$. These data suggest that miR-10b-5p and miR-363-3p are potential biomarkers for RCC tumorigenesis. In relation to this observation, a recent report indicated that miR-10b-5p and miR-363-3p are notably downregulated in tumors of RCC patients who developed tumor relapse (54). This result strongly suggests that miR-10b-5p and miR-363-3p possess tumor suppressive function in RCC development.

Furthermore, to validate that lower expression levels of miR-10b-5p and miR-363-3p mediate the upregulation of $C R E B 1$ to promote RCC tumorigenicity, the RNA of the 35 paired clinical specimens was reversed to cDNA to compare the expression level of miR-10b-5p and miR-363-3p between RCC tissues and ANTs. In contrast, while expression of CREBl in RCC tissues was significantly higher than that in ANTs, miR-10b-5p and miR-363-3p were significantly expressed at lower levels in the RCC tissues. Through upregulation of miR-10b-5p and miR-363-3p, we confirmed the tumor suppressive functions of miR-10b-5p and miR-363-3p by MTT, wound scratch, transwell migration and cell apoptosis assays.

In conclusion, CREBI is overexpressed and has an oncogenic activity in RCC. miR-10b-5p and miR-363-3p suppress CREB1 mRNA and protein expression via the conserved seed region of miR-10b-5p and miR-363-3p within the 3'-UTR of CREB1 mRNA. Importantly, the expression of miR-10b-5p and miR-363-3p was correlated inversely with the CREB1 expression level in 35 paired RCC tissues. In addition, upregulation of miR-10b-5p and miR-363-3p mediated downregulation of CREBI which inhibited RCC tumorigenicity. Taken together, a novel miRNA low expression-dependent upregulation of $C R E B 1$ expression is important for the initiation and development of RCC. However, one future challenge will be to elucidate the miRNA and CREBl-mediated regulatory networks in RCC.

\section{Acknowledgements}

This study was supported by the National Natural Science Foundation of China (no. 81101922), the Guangdong Natural Science Foundation (no. 2015A030313889), the Science and Technology Development Fund Project of Shenzhen (nos. JCYJ20120616144352139, JCYJ20130402114702124, JCYJ20140415162542975 and JCYJ20150403091443329) and the Fund of Guangdong Key Medical Subject.

\section{References}

1. Ridge CA, Pua BB and Madoff DC: Epidemiology and staging of renal cell carcinoma. Semin Intervent Radiol 31: 3-8, 2014.

2. Ferlay J, Shin H-R, Bray F, Forman D, Mathers C and Parkin DM: Estimates of worldwide burden of cancer in 2008: GLOBOCAN 2008. Int J Cancer 127: 2893-2917, 2010.

3. Natural Cancer Institute: Surveillance, epidemiology, and end results program. SEER Stat Fact Sheets: Kidney and renal pelvis cancer. http://seer.cancer.gov/statfacts/html/kidrp.html. Accessed Jan 20,2015.

4. ZhejiangChannelXNA:Worldkidneyday:Kidneycancerincidence increased year by year become 'invisible killer'. http://www. zj.xinhuanet.com/newscenter/science/2014-03/13/c_119759340. htm. Accessed March 13, 2014

5. Chen W, Zheng R, Zhang S, Zhao P, Zeng H, Zou X and He J: Annual report on status of cancer in China, 2010. Chin J Cancer Res 26: 48-58, 2014.
6. Motzer RJ, Bander NH and Nanus DM: Renal-cell carcinoma. N Engl J Med 335: 865-875, 1996.

7. Sakamoto KM and Frank DA: CREB in the pathophysiology of cancer: Implications for targeting transcription factors for cancer therapy. Clin Cancer Res 15: 2583-2587, 2009.

8. Shankar DB, Cheng JC, Kinjo K, Federman N, Moore TB, Gill A, Rao NP, Landaw EM and Sakamoto KM: The role of CREB as a proto-oncogene in hematopoiesis and in acute myeloid leukemia. Cancer Cell 7: 351-362, 2005.

9. Park JK, Park SH, So K, Bae IH, Yoo YD and Um HD: ICAM-3 enhances the migratory and invasive potential of human non-small cell lung cancer cells by inducing MMP-2 and MMP-9 via Akt and $C R E B$. Int J Oncol 36: 181-192, 2010.

10. Zhang M, Xu JJ, Zhou RL and Zhang QY: cAMP responsive element binding protein-1 is a transcription factor of lysosomal-associated protein transmembrane-4 Beta in human breast cancer cells. PLoS One 8: e57520, 2013.

11. Perry C,SklanEH and Soreq H: CREB regulates AChE-R-induced proliferation of human glioblastoma cells. Neoplasia 6: 279-286, 2004.

12. Shukla A, Bosenberg MW, MacPherson MB, Butnor KJ, Heintz NH, Pass HI, Carbone M, Testa JR and Mossman BT: Activated cAMP response element binding protein is overexpressed in human mesotheliomas and inhibits apoptosis. Am J Pathol 175: 2197-2206, 2009.

13. Horvath A, Boikos S, Giatzakis C, Robinson-White A, Groussin L, Griffin KJ, Stein E, Levine E, Delimpasi G, Hsiao HP, et al: A genome-wide scan identifies mutations in the gene encoding phosphodiesterase 11A4 (PDE11A) in individuals with adrenocortical hyperplasia. Nat Genet 38: 794-800, 2006

14. Coxon A, Rozenblum E, Park YS, Joshi N, Tsurutani J, Dennis PA, Kirsch IR and Kaye FJ: Mect1-Maml2 fusion oncogene linked to the aberrant activation of cyclic AMP/CREB regulated genes. Cancer Res 65: 7137-7144, 2005.

15. Siu YT and Jin DY: CREB - a real culprit in oncogenesis. FEBS J 274: 3224-3232, 2007.

16. Ahn S, Olive M, Aggarwal S, Krylov D, Ginty DD and Vinson C: A dominant-negative inhibitor of CREB reveals that it is a general mediator of stimulus-dependent transcription of c-fos. Mol Cell Biol 18: 967-977, 1998.

17. Desdouets C, Matesic G, Molina CA, Foulkes NS, SassoneCorsi $\mathrm{P}$, Brechot $\mathrm{C}$ and Sobczak-Thepot $\mathrm{J}$ : Cell cycle regulation of cyclin A gene expression by the cyclic AMP-responsive transcription factors CREB and CREM. Mol Cell Biol 15: 3301-3309, 1995.

18. White PC, Shore AM, Clement M, McLaren J, Soeiro I, Lam EW and Brennan P: Regulation of cyclin D2 and the cyclin D2 promoter by protein kinase A and CREB in lymphocytes. Oncogene 25: 2170-2180, 2006.

19. Mayr B and Montminy M: Transcriptional regulation by the phosphorylation-dependent factor CREB. Nat Rev Mol Cell Biol 2: 599-609, 2001.

20. Impey S, McCorkle SR, Cha-Molstad H, Dwyer JM, Yochum GS, Boss JM, McWeeney S, Dunn JJ, Mandel G and Goodman RH: Defining the CREB regulon: A genome-wide analysis of transcription factor regulatory regions. Cell 119: 1041-1054, 2004.

21. Zhang X, Odom DT, Koo SH, Conkright MD, Canettieri G, Best J, Chen H, Jenner R, Herbolsheimer E, Jacobsen E, et al: Genome-wide analysis of cAMP-response element binding protein occupancy, phosphorylation, and target gene activation in human tissues. Proc Natl Acad Sci USA 102: 4459-4464, 2005.

22. Krol J, Loedige I and Filipowicz W: The widespread regulation of microRNA biogenesis, function and decay. Nat Rev Genet 11: 597-610, 2010.

23. Bartel DP: MicroRNAs: Target recognition and regulatory functions. Cell 136: 215-233, 2009.

24. Carthew RW and Sontheimer EJ: Origins and mechanisms of miRNAs and siRNAs. Cell 136: 642-655, 2009.

25. Huntzinger E and Izaurralde E: Gene silencing by microRNAs: Contributions of translational repression and mRNA decay. Nat Rev Genet 12: 99-110, 2011.

26. Maher ER: Genomics and epigenomics of renal cell carcinoma. Semin Cancer Biol 23: 10-17, 2013.

27. Chow TF, Mankaruos M, Scorilas A, Youssef Y, Girgis A, Mossad S, Metias S, Rofael Y, Honey RJ, Stewart R, et al: The miR-17-92 cluster is over expressed in and has an oncogenic effect on renal cell carcinoma. J Urol 183: 743-751, 2010. 
28. Müller S and Nowak K: Exploring the miRNA-mRNA regulatory network in clear cell renal cell carcinomas by next-generation sequencing expression profiles. BioMed Res Int 2014: 948408, 2014.

29. Liu H, Brannon AR, Reddy AR, Alexe G, Seiler MW, Arreola A, Oza JH, Yao M, Juan D, Liou LS, et al: Identifying mRNA targets of microRNA dysregulated in cancer: With application to clear cell renal cell carcinoma. BMC Syst Biol 4: 51, 2010.

30. Juan D, Alexe G, Antes T, Liu H, Madabhushi A, Delisi C, Ganesan S, Bhanot G and Liou LS: Identification of a microRNA panel for clear-cell kidney cancer. Urology 75: 835-841, 2010.

31. Yi Z, Fu Y, Zhao S, Zhang X and Ma C: Differential expression of miRNA patterns in renal cell carcinoma and nontumorous tissues. J Cancer Res Clin Oncol 136: 855-862, 2010.

32. White NM, Khella HW, Grigull J, Adzovic S, Youssef YM, Honey RJ, Stewart R, Pace KT, Bjarnason GA, Jewett MA, et al miRNA profiling in metastatic renal cell carcinoma reveals a tumour-suppressor effect for miR-215. Br J Cancer 105: $1741-1749,2011$

33. Wu X, Weng L, Li X, Guo C, Pal SK, Jin JM, Li Y, Nelson RA, $\mathrm{Mu} \mathrm{B}$, Onami SH, et al: Identification of a 4-microRNA signature for clear cell renal cell carcinoma metastasis and prognosis. PLoS One 7: e35661, 2012.

34. Taylor AK, Klisak I, Mohandas T, Sparkes RS, Li C, Gaynor R and Lusis AJ: Assignment of the human gene for CREB1 to chromosome 2q32.3-q34. Genomics 7: 416-421, 1990.

35. Janz S: Myc translocations in B cell and plasma cell neoplasms. DNA Repair (Amst) 5: 1213-1224, 2006.

36. Tan X, Wang S, Zhu L, Wu C, Yin B, Zhao J, Yuan J, Qiang B and Peng $\mathrm{X}$ : cAMP response element-binding protein promotes gliomagenesis by modulating the expression of oncogenic microRNA-23a. Proc Natl Acad Sci USA 109: 15805-15810, 2012.

37. Antonescu CR, Nafa K, Segal NH, Dal Cin P and Ladanyi M: EWS-CREB1: A recurrent variant fusion in clear cell sarcoma - association with gastrointestinal location and absence of melanocytic differentiation. Clin Cancer Res 12: 5356-5362, 2006.

38. Hallor KH, Micci F, Meis-Kindblom JM, Kindblom LG, Bacchini P, Mandahl N, Mertens F and Panagopoulos I: Fusion genes in angiomatoid fibrous histiocytoma. Cancer Lett 251: $158-163,2007$.

39. Tonon G, Modi S, Wu L, Kubo A, Coxon AB, Komiya T, O'Neil K, Stover K, El-Naggar A, Griffin JD, et al: $\mathrm{t}(11 ; 19)$ (q21; p13) translocation in mucoepidermoid carcinoma creates a novel fusion product that disrupts a Notch signaling pathway. Nat Genet 33: 208-213, 2003

40. Kwok RP, Laurance ME, Lundblad JR, Goldman PS, Shih H, Connor LM, Marriott SJ and Goodman RH: Control of cAMP-regulated enhancers by the viral transactivator Tax through CREB and the co-activator CBP. Nature 380: 642-646, 1996.

41. Baranger AM, Palmer CR, Hamm MK, Giebler HA, Brauweiler A, Nyborg JK and Schepartz A: Mechanism of DNA-binding enhancement by the human T-cell leukaemia virus transactivator Tax. Nature 376: 606-608, 1995.

42. Maguire HF, Hoeffler JP and Siddiqui A: HBV X protein alters the DNA binding specificity of CREB and ATF- 2 by protein-protein interactions. Science 252: 842-844, 1991.

43. Barnabas S, Hai T and Andrisani OM: The hepatitis B virus $X$ protein enhances the DNA binding potential and transcription efficacy of bZip transcription factors. J Biol Chem 272: 20684-20690, 1997.
44. Katoh Y, Takemori H, Lin XZ, Tamura M, Muraoka M, Satoh T, Tsuchiya Y, Min L, Doi J, Miyauchi A, et al: Silencing the constitutive active transcription factor CREB by the LKB1-SIK signaling cascade. FEBS J 273: 2730-2748, 2006.

45. Chen L, Yang Q, Kong WQ, Liu T, Liu M, Li X and Tang H: MicroRNA-181b targets cAMP responsive element binding protein 1 in gastric adenocarcinomas. IUBMB Life 64: 628-635, 2012.

46. Kong WQ, Bai R, Liu T, Cai CL, Liu M, Li X and Tang H: MicroRNA-182 targets cAMP-responsive element-binding protein 1 and suppresses cell growth in human gastric adenocarcinoma. FEBS J 279: 1252-1260, 2012.

47. Peng $\mathrm{B}, \mathrm{Hu} \mathrm{S}$, Jun $\mathrm{Q}$, Luo D, Zhang $\mathrm{X}$, Zhao $\mathrm{H}$ and Li D: MicroRNA-200b targets CREB1 and suppresses cell growth in human malignant glioma. Mol Cell Biochem 379: 51-58, 2013.

48. Pigazzi M, Manara E, Bresolin S, Tregnago C, Beghin A, Baron E, Giarin E, Cho EC, Masetti R, Rao DS, et al: MicroRNA-34b promoter hypermethylation induces CREB overexpression and contributes to myeloid transformation. Haematologica 98: 602-610, 2013.

49. Yang Z, Tsuchiya H, Zhang Y, Hartnett ME and Wang L: MicroRNA-433 inhibits liver cancer cell migration by repressing the protein expression and function of cAMP response element-binding protein. J Biol Chem 288: 28893-28899, 2013.

50. Qian J, Li R, Wang YY, Shi Y, Luan WK, Tao T, Zhang JX, $\mathrm{Xu}$ YC and You YP: miR-1224-5p acts as a tumor suppressor by targeting CREB1 in malignant gliomas. Mol Cell Biochem 403: 33-41, 2015.

51. Tan X, Wang S, Yang B, Zhu L, Yin B, Chao T, Zhao J, Yuan J, Qiang B and Peng X: The CREB-miR-9 negative feedback minicircuitry coordinates the migration and proliferation of glioma cells. PLoS One 7: e49570, 2012.

52. Pigazzi M, Manara E, Baron E and Basso G: miR-34b targets cyclic AMP-responsive element binding protein in acute myeloid leukemia. Cancer Res 69: 2471-2478, 2009.

53. Heinzelmann J, Henning B, Sanjmyatav J, Posorski N, Steiner T, Wunderlich H, Gajda MR and Junker K: Specific miRNA signatures are associated with metastasis and poor prognosis in clear cell renal cell carcinoma. World J Urol 29: 367-373, 2011.

54. Slaby O, Redova M, Poprach A, Nekvindova J, Iliev R, Radova L, Lakomy R, Svoboda M and Vyzula R: Identification of microRNAs associated with early relapse after nephrectomy in renal cell carcinoma patients. Genes Chromosomes Cancer 51: 707-716, 2012.

55. Li M, Guan X, Sun Y, Mi J, Shu X, Liu F and Li C: miR-92a family and their target genes in tumorigenesis and metastasis. Exp Cell Res 323: 1-6, 2014.

56. Sun Q, Zhang J, Cao W, Wang X, Xu Q, Yan M, Wu X and Chen W: Dysregulated miR-363 affects head and neck cancer invasion and metastasis by targeting podoplanin. Int $\mathrm{J}$ Biochem Cell Biol 45: 513-520, 2013.

57. Han H, Sun D, Li W, Shen H, Zhu Y, Li C, Chen Y, Lu L, Li W, Zhang J, et al: A c-Myc-microRNA functional feedback loop affects hepatocarcinogenesis. Hepatology 57: 2378-2389, 2013.

58. Zhou P, Huang G, Zhao Y, Zhong D, Xu Z, Zeng Y, Zhang Y, Li S and He F: MicroRNA-363-mediated downregulation of S1PR1 suppresses the proliferation of hepatocellular carcinoma cells. Cell Signal 26: 1347-1354, 2014. 